\title{
The role of seasonality on the diet and household food security of pregnant women living in rural Bangladesh: a cross-sectional study
}

\author{
Briony Stevens ${ }^{1, *}$, Kerrianne Watt ${ }^{1}$, Julie Brimbecombe ${ }^{2}$, Alan Clough ${ }^{1,3,4,5}$, \\ Jenni Judd ${ }^{3,4,6,7}$ and Daniel Lindsay ${ }^{1}$ \\ ${ }^{1}$ School of Public Health, Tropical Medicine and Veterinary Sciences, James Cook University, Townsville, QLD 4811 , \\ Australia: ${ }^{2}$ Menzies School of Health Research, Darwin, NT, Australia: ${ }^{3}$ Anton Breinl Centre for Health Systems \\ Strengthening, James Cook University, Townsville, QLD, Australia: ${ }^{4}$ Australian Institute of Tropical Health and \\ Medicine, James Cook University, Townsville, QLD, Australia: ${ }^{5}$ Centre for Research Excellence in the Prevention of \\ Chronic Conditions in Rural and Remote Populations, James Cook University, Cairns, QLD, Australia: ${ }^{6}$ College of \\ Medicine and Dentistry, James Cook University, Townsville, QLD, Australia: ${ }^{7}$ School of Public Health and Social \\ Work, Queensland University of Technology, Kelvin Grove, QLD, Australia
}

Submitted 12 December 2015: Final revision received 24 May 2016: Accepted 7 June 2016: First published online 30 August 2016

\begin{abstract}
Objective: To investigate the association of seasonality with dietary diversity, household food security and nutritional status of pregnant women in a rural district of northern Bangladesh.

Design: A cross-sectional study was conducted from February 2013 to February 2015. Data were collected on demographics, household food security (using the Household Food Insecurity Access Scale), dietary diversity (using the women's dietary diversity questionnaire) and mid-upper arm circumference. Descriptive statistics were used to explore demographics, dietary diversity, household food security and nutritional status, and inferential statistics were applied to explore the role of seasonality on diversity, household food security and nutritional status.

Setting: Twelve villages of Pirganj sub-district, Rangpur District, northern Bangladesh.

Subjects: Pregnant women ( $n$ 288).

Results: Seasonality was found to be associated with dietary diversity $(P=0.026)$ and household food security $(P=0 \cdot 039)$. Dietary diversity was significantly lower in summer $(P=0.029)$ and spring $(P=0.038)$. Food security deteriorated significantly in spring $(P=0 \cdot 006)$ and late autumn $(P=0 \cdot 009)$.

Conclusion: Seasons play a role in women's household food security status and dietary diversity, with food security deteriorating during the lean seasons and dietary diversity deteriorating during the second 'lesser' lean season and the season immediately after. Interventions that aim to improve the diet of pregnant women from low-income, subsistence-farming communities need to recognise the role of seasonality on diet and food security and to incorporate initiatives to prevent seasonal declines.
\end{abstract}

Keywords Maternal undernutrition Bangladesh Low-income country Women's dietary diversity scores Household Food Insecurity Access Scale
Birth weight is an important indicator of early childhood survival and health. Low-birth-weight babies are at an increased risk of stunting, infant mortality and morbidity, poor cognitive development, and chronic diseases such as diabetes and CVD later in life ${ }^{(1)}$. In low- and middle-income countries, maternal undernutrition contributes to intrauterine growth restriction, which results in low birth weight ${ }^{(1,2)}$. Good nutrition during pregnancy is essential for ensuring fetal growth and development and subsequent childhood health and survival. While studies have identified effective supplementation interventions to address maternal undernutrition in low-income countries, the causes of maternal undernutrition in different contexts remain relatively unexplored ${ }^{(3,4)}$. To design programmes that address maternal undernutrition, organisations often assess food security and dietary diversity using tools that provide a snapshot of the situation at one point in time. Dietary diversity over a reference period acts as a proxy indicator of dietary quality and is associated with nutrient adequacy $^{(5,6)}$. Household food security status reflects availability, accessibility and utilisation of food at a household level. Both dietary diversity and household food security are associated with access to and availability of foods, and seasonality is recognised as a key element of 
food availability in many low-income countries. While it may appear logical for seasonality to be associated with dietary diversity and household food security, programme decision makers rarely consider seasonality when designing new programmes to address maternal undernutrition.

Bangladesh has among the highest rates of maternal and child undernutrition globally. One in three pregnant women is undernourished (BMI $<18.5 \mathrm{~kg} / \mathrm{m}^{2}$ ), one in five babies is born with low birth weight, and one in three children aged 6-59 months is stunted ${ }^{(7,8)}$. In Bangladesh, the times of the year when there are seasonal fluctuations in income and employment are referred to as 'monga'. Monga occurs twice annually: the main monga occurs from 15 September to 14 November (Bangladeshi months of Ashbin and Kartik), prior to the main rice harvest, and the lesser monga occurs from 15 March to 14 April (Bangladeshi month of Choitro) ${ }^{(9)}$. During monga Bangladeshis face seasonal food shortages that often result in household food shortages, particularly among those in rural areas who rely on subsistence farming. The documented consequences of seasonal food shortages on the nutritional status of women in low-income countries include reduced energy expenditure, weight loss, insufficient weight gain and subsequent low birth weight ${ }^{(10-12)}$. Despite a number of studies exploring the role of seasonality on dietary diversity and household food security status at specific time points (often pre and post the lean or monsoon season), the role of annual seasonal variations on dietary diversity and household food security, especially among pregnant women, remains largely unknown $^{(13,14)}$. By understanding seasonal fluctuations in dietary diversity and household food security among pregnant women, programme decision makers can better design interventions to address maternal undernutrition.

The aim of the present study was to investigate the role of seasonality on dietary diversity and household food security for pregnant women living in rural Bangladesh. We also explored relationships of seasonality with maternal nutritional status. We anticipate that these findings will highlight the importance of understanding seasonal variations in maternal dietary diversity and household food security and inform the design of future nutrition interventions in Bangladesh and other lowincome contexts.

\section{Methods}

\section{Study design}

A cross-sectional study was conducted. Recruitment occurred over the period February 2013 to February 2015. The sample consisted of individuals from all villages previously selected for a cluster randomised controlled trial which aimed to measure the effect of a locally produced food-based supplement on reducing intra-uterine growth restriction in undernourished pregnant women. While the sample for the cluster randomised controlled trial consisted of undernourished pregnant women only, the current study looked at all pregnant women from these villages, regardless of their nutritional status. Therefore, participants for the current sample were from two purposively selected unions in Pirganj sub-district, one selected as the intervention and the other matched as the control. From the intervention union, eight villages were randomly selected using computer-generated random numbers. From the control union, four villages were purposively matched. The number of villages was determined based on average population number, prevalence and estimated incidence of pregnant women across the study period, and the required sample size. The data used for the current study come from surveys completed by consenting women confirmed to be pregnant within the twelve villages of interest.

\section{Setting}

The study was conducted in twelve rural villages of Pirganj sub-district of Rangpur District, located in northern Bangladesh. According to the 2011 Population and Housing Census, Pirganj sub-district covers an area of $411.34 \mathrm{~km}^{2}$, consists of 332 villages and has 385499 inhabitants ${ }^{(15)}$. The majority of the population is Muslim, with a minority of people belonging to the Santal ethnic group who are predominantly Christian. The average household size is 3.78 and the literacy rate* is $45 \cdot 4 \%^{(15)}$. The area has a tropical monsoon climate, and experiences high temperatures and humidity and heavy seasonal rainfall from June to November. Rangpur is commonly referred to as 'monga prone' and reported as more vulnerable to seasonal food insecurity than other areas of Bangladesh ${ }^{(16)}$. Rangpur's main employment source is agricultural labour, although wages are very low compared with neighbouring districts $^{(9)}$. The villages are typical of villages in northern Bangladesh and have dirt road access that is often inaccessible during the wet season. The communities are largely dependent on subsistence farming and have limited experience with non-Bangladeshi foods.

\section{Participants and recruitment}

In each of the selected villages, all women were invited to participate in the study if they: (i) were suffering no illness requiring medical referral; and (ii) were confirmed to be pregnant by a midwife, skilled community health volunteer or other health professional. Prior to the commencement of the study, eight female community nutrition volunteers and two (one male, one female) supervisors from the selected villages were trained on the basics of nutrition, study purpose and design. The community nutrition volunteers had at least a primary-school

\footnotetext{
* Defined as the ability to write a letter in any language, assessed among
} the population 7 years and above ${ }^{(15)}$. 
education, spoke the local dialect, and were aged between 21 and 49 years. Community nutrition volunteers compiled lists of all pregnant women in the twelve villages and produced village maps that determined the location of each woman's household. These women were identified through community discussions, door-knocking and snowballing. If the woman was interested, the community nutrition volunteer then verified that she met the inclusion criteria and referred the woman to a skilled health worker if the pregnancy was not yet confirmed. Women were given a brief overview of the project and invited to participate. Written or verbal (with thumbprint) consent to participate was obtained after participants heard the project information sheet read aloud. A copy of the information sheet in the local language was provided to participants for their further reference. Verbal consent was also obtained from the leaders of each village for inclusion of their village in the study.

The current project had human research ethical approval from the James Cook University (Australia) Ethics Committee (H4498) and the Bangladesh Medical Research Council (BMRC/NREC/2010-2013/58). The research was registered with the ISRCTN registry (ISRCTN97447076).

\section{Data collection}

The community nutrition volunteers assisted participants to complete a survey comprising: (i) background demographics; (ii) household food security; (iii) dietary diversity; and (iv) anthropometry. We used the validated Food and Nutrition Technical Assistance Project's Household Food Insecurity Access Scale (HFIAS) questionnaire and the validated FAO dietary diversity questionnaire to explore food security and dietary diversity, respectively ${ }^{(17-19)}$. The HFIAS questionnaire consisted of nine occurrence questions (conditions) and nine frequency-ofoccurrence questions. With a recall period of $30 \mathrm{~d}$, each occurrence question reflected a condition that represented an increasing level of severity of food insecurity (access) and the frequency-of-occurrence questions determined how often the condition occurred. The nine questions were grouped to form three domains to provide additional information on anxiety and uncertainty about household food supplies, insufficient quality and insufficient food intake and its physical consequences. The frequency-ofoccurrence questions were also used to calculate scores, which were then grouped into two categories: food secure and food insecure ${ }^{(19)}$. The dietary diversity questionnaire consisted of thirteen questions that were later aggregated to form nine food groups. With a recall period of $24 \mathrm{~h}$, this questionnaire allowed us to calculate the woman's dietary diversity score (WDDS), identify individual food groups consumed and calculate specific indicators of interest for micronutrient-rich food groups ${ }^{(20)}$. The study lead author adapted the HFIAS and dietary diversity questionnaires through community dialogue ${ }^{(21)}$. The HFIAS questionnaire was adapted to ensure a common understanding of certain words (e.g. a locally appropriate definition of 'household' and 'meal'). The dietary diversity questionnaire was adapted to reflect locally available foods. Questionnaires were translated into local terminology, back-translated and field-tested prior to use. In addition, an interviewer's guide was developed to provide additional information on each question, as well as examples to ensure that questions were understood appropriately.

Mid-upper arm circumference (MUAC) measurements were performed using the standardised procedures recommended by the $\mathrm{WHO}^{(22)}$. The community nutrition volunteer took duplicate measurements of the left arm measured to the nearest millimetre with adult MUAC tapes. Triplicate measurements were taken if a variation occurred between the two measurements. Maternal undernutrition was defined as MUAC $\leq 22 \cdot 1 \mathrm{~cm}$. MUAC was the preferred indicator to identify maternal undernutrition based on its association with low birth weight ${ }^{(23,24)}$. The cut-off was determined after a review of the evidence and a discussion with organisations conducting nutrition programmes and research in Bangladesh ${ }^{(24)}$.

\section{Statistical methods}

The STROBE (Strengthening the Reporting of Observational Studies in Epidemiology) Checklist for crosssectional studies was used to ensure comprehensive reporting of the present study. Data management was performed using the statistical software package IBM SPSS Statistics, Version 23.0@. Data quality was ensured by quality checks associated with the data-entry process, double entry and data cleaning.

\section{Food insecurity}

Household food insecurity was determined using the HFIAS for Measurement of Food Access: Indicator Guide, Version 3. Dichotomous occurrence and ordinal frequency categorical variables were created for each condition; frequencies for each food insecurity access domain (anxiety, food quality and food quantity) and HFIAS scores were used to identify the prevalence of different levels of household food insecurity ${ }^{(19)}$.

\section{Dietary diversity}

Women's dietary diversity was determined using the FAO guidelines to measure household and individual dietary diversity $^{(18)}$. Dietary diversity was summarised to create dichotomous occurrence variables for each food group and indicators of specific interest, and aggregated to create the $\operatorname{WDDS}^{(18)}$. The nine food groups were: (i) starchy staples; (ii) dark green leafy vegetables; (iii) vitamin A-rich fruits/vegetables; (iv) other fruits/vegetables; (v) organ meats; (vi) meat/poultry/fish; (vii) eggs; (viii) legumes/ nuts/seeds; and (ix) milk/milk products. The WDDS were used as discrete quantitative variables and divided into 
tertiles to distinguish diets of high, medium and low diversity. As there are no universally agreed cut-offs to define WDDS tertiles, we created tertiles based on recommendations in current literature ${ }^{(6)}$. After aggregating household food security and dietary diversity according to the respective guidelines, we analysed the means of the variables, with a higher HFIAS indicating more food insecure and a lower WDDS indicating lower dietary diversity. To explore consumption of vitamin A- and Ferich foods, indicators from specific related food groups were created ${ }^{(18)}$

Household food security, dietary diversity and nutritional status were used as dependent variables and differences in these variables were examined based on the season variable. Grouping questionnaires by the six Bangladeshi seasons (summer $=15$ April-14 June; monsoon $=15$ June-14 August; autumn=15 August-14 October; late autumn $=15$ October-14 December; winter $=15$ December-14 February; spring $=15$ February -14 April) created the season variable. We used inferential statistics to test for relationships and differences between the variables of interest.

Data were not normally distributed, so non-parametric tests were used. Questions related to food security, dietary diversity and anthropometry based on season were analysed using the Kruskal-Wallis one-way ANOVA by ranks test followed by the post hoc Mann-Whitney $U$ test. Comparisons between frequencies of participants' responses on the dietary diversity and food security variables were analysed using the $\chi^{2}$ test. Statistical significance was accepted at $P<0 \cdot 05$.

\section{Results}

\section{Participants}

From February 2013 to February 2015, 289 pregnant women were identified as potentially eligible. One woman refused participation for unknown reasons. Thus, a total of 288 women were enrolled in the study.

\section{Descriptive data}

Background characteristics of the 288 women surveyed are presented in Table 1 . The mean age of women was 25.3 (SD 5.7) years. Most women had attended school, with the majority reaching either primary or lower secondary education ( 42.0 and $42.4 \%$, respectively). The mean height of women was $148.5(\mathrm{sD} 7.7) \mathrm{cm}$, with almost half of women below $148 \mathrm{~cm}(47.4 \%)$. The mean MUAC of women was 23.73 (SD 2.27) cm, with $29.7 \%$ of women below $22 \cdot 1 \mathrm{~cm}$. Most women were in their second trimester $(54.9 \%)$ of their pregnancy. Of women in the first trimester ( $n$ 85), the mean BMI was $20 \cdot 4$ (SD 3.4$) \mathrm{kg} / \mathrm{m}^{2}$. One in three women reported that she was experiencing pregnancy for the first time (36.5\%).
Table 1 Background characteristics of participating pregnant women $(n 288)$ from twelve villages in rural northern Bangladesh, February 2013-February 2015

\begin{tabular}{|c|c|c|c|c|}
\hline Background characteristic & $n$ & $\%$ & Mean & SD \\
\hline Maternal age (years) & & & $25 \cdot 3$ & $5 \cdot 7$ \\
\hline \multicolumn{5}{|l|}{ Trimester } \\
\hline First & 87 & 32.5 & & \\
\hline Second & 147 & 54.9 & & \\
\hline Third & 34 & $12 \cdot 7$ & & \\
\hline Lived at village since birth & 287 & 99.7 & & \\
\hline Married & 288 & $100 \cdot 0$ & & \\
\hline Average household size & & & 3.6 & 1.4 \\
\hline Male head of household & 288 & $100 \cdot 0$ & & \\
\hline \multicolumn{5}{|l|}{ School attendance } \\
\hline Never attended & 27 & 9.4 & & \\
\hline Primary & 121 & $42 \cdot 0$ & & \\
\hline Lower secondary* & 122 & $42 \cdot 4$ & & \\
\hline Higher secondary $\dagger$ & 16 & $5 \cdot 6$ & & \\
\hline Tertiary & 2 & 0.7 & & \\
\hline \multicolumn{5}{|l|}{ Religion } \\
\hline Islam & 246 & 85.4 & & \\
\hline Hindu & 32 & $11 \cdot 1$ & & \\
\hline Christianity & 10 & 3.5 & & \\
\hline \multicolumn{5}{|l|}{ Gravidity } \\
\hline 0 & 106 & $37 \cdot 1$ & & \\
\hline 1 & 121 & $42 \cdot 3$ & & \\
\hline 2 & 44 & $15 \cdot 4$ & & \\
\hline$\geq 3$ & 15 & $5 \cdot 1$ & & \\
\hline First pregnancy & 105 & $36 \cdot 5$ & & \\
\hline Still birth & 11 & 3.8 & & \\
\hline Miscarriage & 19 & $6 \cdot 6$ & & \\
\hline $\begin{array}{l}\text { Woman works outside home, } \\
\text { excluding housework }\end{array}$ & 36 & $12 \cdot 5$ & & \\
\hline \multicolumn{5}{|l|}{ Anthropometrics } \\
\hline Maternal height $(\mathrm{cm})$ & & & 148.5 & $7 \cdot 7$ \\
\hline Maternal height $<148 \mathrm{~cm}$ & 136 & 47.4 & & \\
\hline Maternal MUAC $(\mathrm{cm})$ & & & 23.7 & $2 \cdot 3$ \\
\hline Maternal MUAC $<22.1 \mathrm{~cm}$ & 85 & $29 \cdot 7$ & & \\
\hline
\end{tabular}

MUAC, mid-upper arm circumference.

${ }^{*}$ Grade $7-10$.

†Grade 11-12

\section{Main results}

Food security

Food security characteristics are presented in Table 2 . The mean HFIAS score was $4 \cdot 06$ (SD 2.86; range 0-13 of a possible 27). Of the women, most were identified as food insecure (87.6\%), with $7 \cdot 7 \%$ identified as severely food insecure.

Dietary diversity

Over nine possible food groups, women's dietary diversity ranged from two to eight food groups. The mean number of food groups consumed was at $4 \cdot 8$ (SD 1.1), indicating low probability of adequate dietary intake ${ }^{(25)}$. Figures 1 and 2 illustrate the food groups consumed by pregnant women. To further explore the frequency of food groups consumed, Table 3 illustrates the food groups consumed by more than $50 \%$ of women by WDDS tertile.

Seasonal variations in dietary diversity and bousebold food security status

Table 4 presents the percentage of participants reporting consuming each food group (dietary diversity) and their 
agreement with various statements in relation to household food security, based on season. The relevant medians and interquartile ranges for these analyses can be seen in Table 5. No significant differences in MUAC based on season were found $(P=0 \cdot 130)$. The median WDDS varied as a function of season $(\mathrm{H}(5)=12 \cdot 97, P=0.026)$.

Table 2 Food security characteristics of pregnant women $(n 288)$ from twelve villages in rural northern Bangladesh, February 2013-February 2015

\begin{tabular}{lrr}
\hline Food security characteristic & $n$ & $\%$ \\
\hline HFIAS category & 35 & \\
Food secure & 59 & $12 \cdot 2$ \\
Mild household food insecurity & 171 & $59 \cdot 6$ \\
Moderate household food insecurity & 22 & $7 \cdot 7$ \\
Severe household food insecurity & & \\
HFIAS conditions & 111 & $38 \cdot 5$ \\
Worry about food intake & 195 & $67 \cdot 7$ \\
Not able to eat preferred foods & 133 & $46 \cdot 2$ \\
Limited variety of foods & 195 & $67 \cdot 7$ \\
Eat unwanted foods & 147 & $51 \cdot 0$ \\
Eat small meals & 40 & $13 \cdot 9$ \\
Eat fewer meals & 11 & $3 \cdot 8$ \\
No food in house & 9 & $3 \cdot 1$ \\
Sleep hungry & 6 & $2 \cdot 1$ \\
Whole day without food & & \\
HFIAS domains & 248 & $86 \cdot 1$ \\
Insufficient food quality & 162 & $56 \cdot 4$ \\
Insufficient food intake & & \\
\hline
\end{tabular}

HFIAS, Household Food Insecurity Access Scale.
Mann-Whitney $U$ tests revealed that the median value for dietary diversity was significantly lower in summer than in late autumn $(U=2202, r=2.19, P=0.029)$ and winter $(U=802.5, r=2 \cdot 21, P=0.027)$ and significantly lower in spring than in late autumn $(U=1286 \cdot 5, r=2 \cdot 08, P=0.038)$ and winter $(U=463.5, \quad r=2.23, \quad P=0.026)$. Chi-square analyses revealed that the consumption of meat/poultry/ fish varied as a function of season $\left(\chi^{2}=11.74, P=0.039\right)$. Based on the percentages presented in Table 4, it appears as though a greater proportion of women consumed meat/ poultry/fish in late autumn and winter compared with other seasons. This may have contributed to the significantly higher number of women eating food groups rich in haem Fe during late autumn and winter compared with other months (see Table $4 ; \chi^{2}=12.9, P=0.034$ ).

A Kruskal-Wallis test determined that the median HFIAS score varied as a function of season $(H(5)=11.68$, $P=0.039)$. Mann-Whitney $U$ tests revealed that the median HFIAS score was significantly higher in spring than in the monsoon season $(U=649.5, r=-2.73, P=0.006)$ and late autumn $(U=1181, r=-2 \cdot 61, P=0 \cdot 009)$. Further analyses of the HFIAS conditions based on season revealed a significant difference in the proportion of participants who reported having to eat a limited variety of foods due to a lack of resources $\left(\chi^{2}=12 \cdot 72, P=0 \cdot 026\right)$. The percentages reported in Table 4 suggest that more participants reported having to eat a limited variety of foods due to a lack of

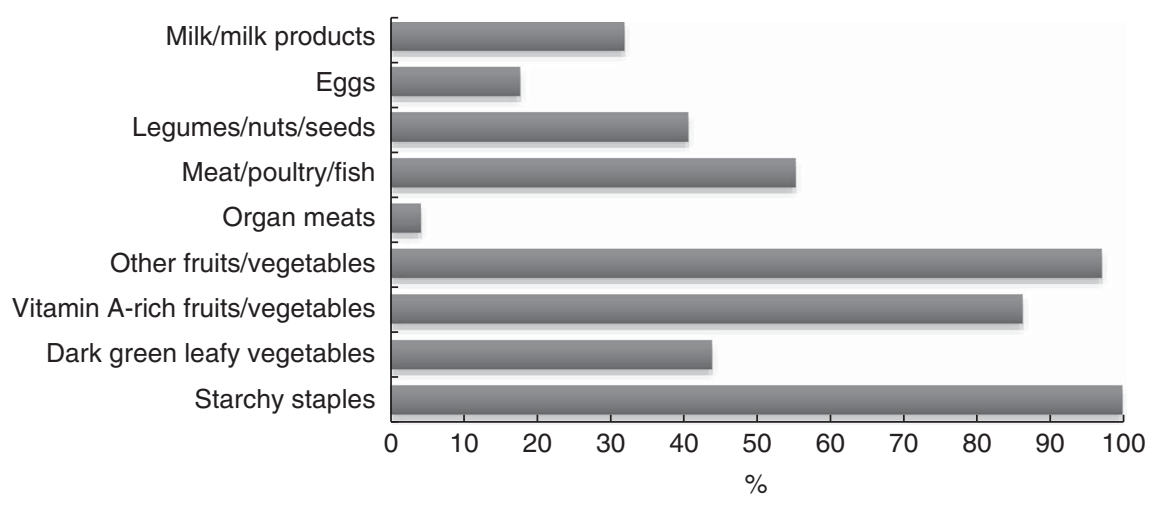

Fig. 1 Food groups consumed over a $24 \mathrm{~h}$ period by pregnant women $(n$ 288) from twelve villages in rural northern Bangladesh, February 2013-February 2015

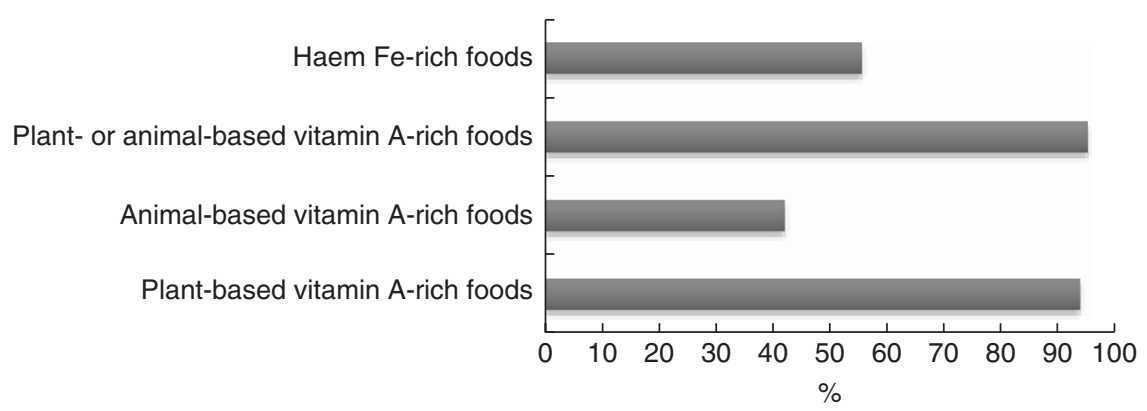

Fig. 2 Micronutrient-rich food groups consumed over a $24 \mathrm{~h}$ period by pregnant women ( $\mathrm{n} 288)$ from twelve villages in rural northern Bangladesh, February 2013-February 2015 
Table 3 Food groups, according to tertile of dietary diversity, consumed by $\geq 50 \%$ of pregnant women ( $n$ 288) from twelve villages in rural northern Bangladesh, February 2013-February 2015

\begin{tabular}{lll}
\hline Lowest dietary diversity ( $\leq 4$ food groups) & Medium dietary diversity $(5$ food groups) & High dietary diversity $(\geq 6$ food groups) \\
\hline Starchy staples & Starchy staples & Starchy staples \\
Dark green leafy vegetables & Dark green leafy vegetables & Dark green leafy vegetables \\
Other vitamin-A rich fruits/vegetables & Other vitamin A-rich fruits/vegetables & Other vitamin A-rich fruits/vegetables \\
Other fruits/vegetables & Other fruits/vegetables & Other fruits/vegetables \\
& Meat/poultry/fish & Meat/poultry/fish \\
& & Legumes/nuts/seeds \\
& & Milk/milk products \\
\hline
\end{tabular}

Table 4 Percentage response to dietary diversity, food security and nutritional status questions as a function of season among pregnant women $(n$ 288) from twelve villages in rural northern Bangladesh, February 2013-February 2015

\begin{tabular}{|c|c|c|c|c|c|c|c|}
\hline & \multicolumn{6}{|c|}{ Season } & \multirow[b]{2}{*}{$\begin{array}{c}P \\
\text { value }\end{array}$} \\
\hline & $\begin{array}{l}\text { Summer } \\
(n \text { 89) }\end{array}$ & $\begin{array}{l}\text { Monsoon } \\
(n 38)\end{array}$ & $\begin{array}{c}\text { Autumn } \\
(n 21)\end{array}$ & $\begin{array}{l}\text { Late autumn } \\
\quad(n 62)\end{array}$ & $\begin{array}{l}\text { Winter } \\
(n 25)\end{array}$ & $\begin{array}{l}\text { Spring } \\
(n 53)\end{array}$ & \\
\hline \multicolumn{8}{|l|}{ Dietary diversity: food groups (\%) } \\
\hline Starchy staples & $100 \cdot 0$ & $100 \cdot 0$ & $100 \cdot 0$ & 98.4 & $100 \cdot 0$ & $100 \cdot 0$ & 0.691 \\
\hline Dark green leafy vegetables & $40 \cdot 4$ & 44.7 & $57 \cdot 1$ & $45 \cdot 2$ & 48.0 & 39.6 & 0.770 \\
\hline Vitamin A-rich fruits/vegetables & 77.5 & $92 \cdot 1$ & 90.5 & $90 \cdot 3$ & 88.0 & 88.7 & 0.205 \\
\hline Other fruits/vegetables & 98.9 & 97.4 & $95 \cdot 2$ & 93.5 & $100 \cdot 0$ & $96 \cdot 2$ & 0.426 \\
\hline Organ meats & $2 \cdot 2$ & $5 \cdot 3$ & 9.5 & 3.2 & 8.0 & 3.8 & 0.457 \\
\hline Meat/poultry/fish & $42 \cdot 7$ & 57.9 & $57 \cdot 1$ & $66 \cdot 1$ & $72 \cdot 0$ & $52 \cdot 8$ & 0.039 \\
\hline Legumes/nuts/seeds & $42 \cdot 7$ & $15 \cdot 4$ & 8.5 & $25 \cdot 2$ & $10 \cdot 2$ & 21.5 & 0.638 \\
\hline Eggs & $16 \cdot 9$ & $21 \cdot 1$ & $19 \cdot 0$ & $21 \cdot 0$ & $16 \cdot 0$ & $13 \cdot 2$ & 0.893 \\
\hline Milk/milk products & 33.7 & 44.7 & $23 \cdot 8$ & 27.4 & $40 \cdot 0$ & 24.5 & 0.278 \\
\hline Plant-based vitamin A-rich foods & $92 \cdot 1$ & 94.7 & 90.5 & 91.9 & $100 \cdot 0$ & $96 \cdot 2$ & 0.662 \\
\hline Animal-based vitamin A-rich foods & 44.9 & 44.7 & $42 \cdot 9$ & 43.5 & 44.0 & $32 \cdot 1$ & 0.753 \\
\hline Haem Fe-rich foods & $42 \cdot 7$ & 57.9 & 61.9 & $66 \cdot 1$ & $72 \cdot 0$ & $52 \cdot 8$ & 0.034 \\
\hline \multicolumn{8}{|l|}{ HFIAS conditions $(\%)$} \\
\hline Not able to eat preferred foods & $65 \cdot 2$ & $63 \cdot 2$ & $76 \cdot 2$ & $61 \cdot 3$ & $68 \cdot 0$ & $79 \cdot 2$ & 0.336 \\
\hline Limited variety of foods & 58.4 & 39.5 & $28 \cdot 6$ & $37 \cdot 1$ & $36 \cdot 0$ & $52 \cdot 8$ & 0.026 \\
\hline Eat unwanted foods & 58.4 & 68.4 & $85 \cdot 7$ & 71.0 & $68 \cdot 0$ & $71 \cdot 7$ & 0.198 \\
\hline Eat small meals & $66 \cdot 3$ & $36 \cdot 8$ & $52 \cdot 4$ & $37 \cdot 1$ & $60 \cdot 0$ & $47 \cdot 2$ & 0.040 \\
\hline Eat fewer meals & $12 \cdot 4$ & $10 \cdot 8$ & 0.0 & $16 \cdot 1$ & $12 \cdot 0$ & $22 \cdot \overline{6}$ & 0.176 \\
\hline No food in house & $5 \cdot 6$ & $2 \cdot 6$ & 0.0 & 1.6 & 8.0 & $3 \cdot 8$ & 0.628 \\
\hline Sleep hungry & $1 \cdot 1$ & 0.0 & 0.0 & 4.8 & 8.0 & 5.7 & 0.197 \\
\hline Whole day without food & $2 \cdot 2$ & 0.0 & 0.0 & $3 \cdot 2$ & 0.0 & 3.8 & 0.899 \\
\hline \multicolumn{8}{|l|}{ HFIAS domains (\%) } \\
\hline Worry about food intake & 37.1 & $21 \cdot 1$ & 42.9 & 33.9 & $52 \cdot 0$ & 50.9 & 0.062 \\
\hline Insufficient food quality & $87 \cdot 6$ & $84 \cdot 2$ & 90.5 & $80 \cdot 6$ & 84.0 & $90 \cdot 6$ & 0.692 \\
\hline Insufficient food intake & $70 \cdot 8$ & 40.5 & $52 \cdot 4$ & 41.9 & $64 \cdot 0$ & 58.5 & 0.004 \\
\hline HFIAS category: food insecure (\%) & 89.9 & $83 \cdot 8$ & $90 \cdot 5$ & 93.9 & 84.0 & 92.5 & 0.619 \\
\hline
\end{tabular}

HFIAS, Household Food Insecurity Access Scale.

Table 5 Median (and interquartile range (IQR)) dietary diversity score, food security score and mid-upper arm circumference (MUAC) as a function of season among pregnant women $(n$ 288) from twelve villages in rural northern Bangladesh, February 2013-February 2015

\begin{tabular}{|c|c|c|c|c|c|c|c|c|c|c|c|c|}
\hline & \multicolumn{12}{|c|}{ Season } \\
\hline & \multicolumn{2}{|c|}{ Summer } & \multicolumn{2}{|c|}{ Monsoon } & \multicolumn{2}{|c|}{ Autumn } & \multicolumn{2}{|c|}{ Late autumn } & \multicolumn{2}{|c|}{ Winter } & \multicolumn{2}{|c|}{ Spring } \\
\hline & Median & IQR & Median & IQR & Median & IQR & Median & IQR & Median & IQR & Median & IQR \\
\hline WDDS & 5 & 1 & 5 & 2 & 5 & 2 & 5 & 2 & 5 & 2 & 4 & 1 \\
\hline HFIAS & 4 & 4 & 3 & 4 & 4 & 4 & 3 & 5.5 & 4 & 5 & 4 & 4.5 \\
\hline MUAC & 24.00 & 3.80 & $22 \cdot 85$ & 3.00 & 24.50 & 3.20 & 23.25 & 2.50 & 24.00 & 3.00 & $22 \cdot 15$ & 2.60 \\
\hline
\end{tabular}

WDDS, woman's dietary diversity score; HFIAS, Household Food Insecurity Access Scale.

resources in the summer and spring seasons than all other seasons. The proportion of participants who reported having to eat a smaller meal than they felt they needed to because there was not enough food also differed significantly based on season $\left(\chi^{2}=17 \cdot 312, P=0.04\right)$. Based on the percentages in Table 4 , it appears as though 
participants reported having to eat a smaller meal less often in the monsoon and late autumn seasons than in all other seasons.

Further analysis of the HFIAS domains revealed a significant difference in the proportion of participants who reported having insufficient food intake across the seasons $\left(\chi^{2}=46.57, P=0.004\right)$. From the percentages presented in Table 4 , it appears as though participants are most concerned about not getting sufficient food intake in the summer and winter seasons.

\section{Seasonal variations in anthropometry}

A Kruskal-Wallis test revealed no significant differences in MUAC based on season $(H(5)=8.53, P>0.05$; see Table 5 for more detail).

\section{Discussion}

In northern Bangladesh, we found that dietary diversity and household food security were sensitive to seasonal variations, a finding which has been observed in similar studies $^{(13,14)}$. Seasonality was significantly associated with dietary diversity and food security status of pregnant women. A common limitation in the use of the HFIAS and women's dietary diversity tools is that they capture a 'snapshot' of the situation and do not reflect seasonal variances. While a few studies have attempted to address this limitation, studies have traditionally been cross-sectional at two points in time ${ }^{(13,14)}$. Our study is unique as it recruited women over a 24 -month period, taking into consideration seasonal variances across the year. A 2-year period was necessary to reach the required sample size to maximise the chance of finding a significant result. Contrary to findings reported elsewhere, we did not identify significant differences in maternal nutritional status based on season ${ }^{(14)}$.

Women had higher dietary diversity in autumn and winter, corresponding with the first month of monga and the month between the main monga and lesser monga, respectively. The higher dietary diversity in autumn corresponded with a higher consumption of dark green leafy vegetables, vitamin A-rich fruits/vegetables and organ meats; while the higher dietary diversity in winter corresponded with a higher consumption of other fruits/vegetables, organ meats, meat/poultry/fish and milk/milk products. Late autumn and winter corresponded with a higher consumption of Fe-rich foods. Interestingly, these two seasons had the lowest consumption of legumes/ nuts/seeds. This may be due to the higher consumption of fresh produce such as fruits, vegetables and meat. During these months, legumes, nuts and seeds may be stored for periods when fresh produce is no longer available or accessible. Women had lower dietary diversity in summer and spring, corresponding with the first month of the lesser monga and the month directly after the lesser monga. This may be due to households depleting food supplies during the main monga and having no reserves for the lesser monga. While the first monga may be considered the 'main' monga due to its longer duration, the effects of the lesser monga may be more detrimental on the nutritional status of pregnant women in the household.

We identified that household food insecurity peaked during monga (autumn) and lesser monga (spring). A similar study conducted in northern Bangladesh, but with a different target group, identified that the prevalence of both food insecurity and undernutrition was higher during the monsoon season compared with the dry season (winter) ${ }^{(14)}$. While our findings may differ, this is likely due to the study methodology; the other study conducted a survey at two points in time only (monsoon and winter) and therefore did not analyse the differences between other seasons. Our findings clearly illustrate fluctuations in dietary diversity and household food security across the seasons. Spring, which corresponds with the lesser monga, had high proportions of participants reporting both low variety of foods and food insecurity. By summer, we continued to see a high proportion of participants reporting low variety of foods, coupled with insufficient food intake, and consumption of smaller sized meals. By autumn, while dietary diversity was higher than in the previous season, household food insecurity remained high. Late autumn, which corresponds to the end of the main monga, appeared to be the most food-secure season where dietary diversity was at its highest and where food insecurity affected the lowest proportion of households for the year.

We did not identify a relationship between seasonality and maternal nutritional status (as measured by MUAC). Recent evidence from a similar study in a neighbouring district of Bangladesh contradicts this ${ }^{(14)}$. In that study, seasonality was associated with nutritional status. However, the target group in Hillbruner and Egan's study was children aged 6-72 months ${ }^{(14)}$ and the target group in the present study was pregnant women. Hence, the conflicting findings may be due to differences in target group. The reason for seasonality not being associated with maternal nutritional status in the present study may be that the negative outcomes of seasonality on dietary diversity and household food security do not last long enough to be associated with maternal nutritional status in the Bangladeshi context. Alternatively, it may be that women are able to mitigate potential associations between seasonal variation and maternal nutritional status by adapting their diet accordingly. The WDDS and HFIAS tools are limited to identifying food groups consumed and classification of household food security status. By using a $24 \mathrm{~h}$ dietary recall tool, further analyses may have explored whether seasonal declines in maternal nutritional status were prevented through changes in the quantity of food consumed.

\section{Study limitations}

Our study had a number of limitations. First, the month of Ramadan resulted in difficulties finding an 'average' day 
for the dietary diversity and household food insecurity questionnaires. To address Ramadan, participants observing Ramadan were rescheduled to complete the interview process on a 'normal' day, even if this meant waiting until after Ramadan. Second, we were unable to control for potential differences in seasonal impacts and differences in women across the 2-year enrolment period due to the small sample size. It is important to note, however, that while Bangladesh is disaster-prone, no natural disasters occurred in the study areas across the study period. Third, both the dietary diversity and household food insecurity questionnaires have a recall period ( $24 \mathrm{~h}$ and $30 \mathrm{~d}$, respectively) which may have resulted in a recall bias. Participants may forget items, and particularly for the dietary diversity questionnaire, the time period may be insufficient to capture the typical food groups consumed by the participant and may capture episodic foods that are not typically consumed. Fourth, respondent bias may also be an issue. In population groups where food assistance or developmental aid assistance is frequent, participants may over-report food insecurity and under-report dietary diversity with the expectation of receiving assistance. Conversely, participants may modify their responses based on social desirability. Lastly, despite our active home visits by the community nutrition volunteers, the proportion of women included early in pregnancy was lower than desired, a limitation experienced by others ${ }^{(26)}$.

\section{Conclusion}

In conclusion, the present study identified that seasonality was significantly associated with dietary diversity and household food security of pregnant women in Pirganj, Bangladesh. Women's household food security status was significantly worse during the two mongas and dietary diversity was significantly lower during the lesser monga and the month immediately after the lesser monga. While the highest annual levels of food security and dietary diversity occurred during the season after the main monga, indicating a quick recovery from the main monga, we identified a high proportion of food insecurity during the lesser monga and an even higher proportion of food insecurity in the season immediately after the lesser monga, potentially indicating that households struggled to recover from the lesser monga. While economic and nutritional support is required during monga, continued support is also required for the period between the lesser monga and the main monga. This support could be through behavioural change strategies, food banks and diversification of household food production. Support during this time may lessen the shocks of the two mongas on household food security and maternal dietary diversity.

Our study highlights the importance of measuring WDDS and HFIAS across the year in order to identify seasonal variations. By recognising these seasonal variations, policy makers and programme decision makers can design context-specific interventions to improve the diet of pregnant women while incorporating initiatives to prevent negative seasonal declines in food security and dietary diversity, thus contributing to better development outcomes for the mother and child.

\section{Acknowledgements}

Acknowledgements: The authors thank the study participants, local communities and World Vision Bangladesh (non-governmental organisation) for their support and for making this research possible. They particularly thank Francis P. Nath and Nomita Sarker from World Vision for supporting community relationships, logistics, translation and back-translation, data storage and data entry. They also thank the community nutrition volunteers for their invaluable enthusiasm to support the study, especially for training participation, assisting with study recruitment and data collection, and for building strong relationships with and within the communities. Funding: This work was supported by World Vision New Zealand. World Vision New Zealand had no role in the design, analysis or writing of this article. Conflict of interest: None. Authorship: B.S. oversaw conception and design, with contributions from J.B., A.C. and J.J. B.S. coordinated the collection of data. B.S. and D.L. performed the data analyses and interpretation with assistance from K.W. B.S. drafted the article. J.J., J.B., A.C., K.W. and D.L. revised the article for important intellectual content. Etbics of buman subject participation: This project had human research ethical approval from the James Cook University (Australia) Ethics Committee (H4498) and the Bangladesh Medical Research Council (BMRC/NREC/2010-2013/58). This research was registered with the ISRCTN registry (ISRCTN97447076).

\section{References}

1. Black RE, Victora CG, Walker SP et al. (2013) Maternal and child undernutrition and overweight in low-income and middle-income countries. Lancet 382, 427-451.

2. Kelly A, Kevany J, de Onis M et al. (1996) A WHO collaborative study of maternal anthropometry and pregnancy outcomes. Int J Gynaecol Obstet 53, 219-323.

3. Ota E, Tobe-Gai R, Mori R et al. (2012) Antenatal dietary advice and supplementation to increase energy and protein intake. Cochrane Database Syst Rev issue 9, CD000032.

4. Stevens B, Buettner P, Watt K et al. (2015) The effect of balanced protein energy supplementation in undernourished pregnant women and child physical growth in low- and middle-income countries: a systematic review and meta-analysis. Matern Child Nutr 11, 415-432.

5. Moursi MM, Arimond M, Dewey KG et al. (2008) Dietary diversity is a good predictor of the micronutrient density of the diet of 6- to 23-month-old children in Madagascar. J Nutr 138, 2448-2453.

6. Ruel MT (2003) Operationalizing dietary diversity: a review of measurement issues and research priorities. J Nutr $\mathbf{1 3 3}$, 11 Suppl. 2, 3911S-3926S. 
7. National Institute of Population Research and Training, Mitra and Associates, \& MEASURE DHS, ICF International (2012) Bangladesh Demographic and Health Survey 2011: Preliminary Report. Text. Dhaka and Calverton, MD: NIPORT, Mitra and Associates, and ICF International.

8. National Institute of Population Research and Training, Mitra and Associates, \& Macro International (2009) Bangladesh Demographic and Health Survey, 2007. Dhaka and Calverton, MD: NIPORT, Mitra and Associates, and Macro International.

9. Zug S (2006) Monga - seasonal food insecurity in Bangladesh - bringing the information together. J Soc Stud (Centre for Social Studies, Dhaka) issue 111(Jul-Sep 2006).

10. Rayco-Solon P, Fulford AJ \& Prentice AM (2005) Differential effects of seasonality on preterm birth and intrauterine growth restriction in rural Africans. Am J Clin Nutr $\mathbf{8 1}$, 134-139.

11. Panter-Brick C (1993) Seasonality of energy expenditure during pregnancy and lactation for rural Nepali women. Am J Clin Nutr 57, 620-628.

12. Roberts SB, Paul AA, Cole TJ et al. (1982) Seasonal changes in activity, birth weight and lactational performance in rural Gambian women. Trans $R$ Soc Trop Med Hyg $\mathbf{7 6}$, 668-678.

13. Savy M, Martin-Prével Y, Traissac P et al. (2006) Dietary diversity scores and nutritional status of women change during the seasonal food shortage in rural Burkina Faso. J Nutr 136, 2625-2632.

14. Hillbruner C \& Egan R (2008) Seasonality, household food security, and nutritional status in Dinajpur, Bangladesh. Food Nutr Bull 29, 221-231.

15. Bangladesh Bureau of Statistics, Statistics and Informatics Division, Ministry of Planning, Government of the People's Republic of Bangladesh (2011) Population and Housing Census 2011. Dhaka: BBS.

16. World Food Programme (2005) Bangladesh Food Security Brief. Dhaka: Vulnerability Analysis and Mapping Unit, WFP Bangladesh.

17. Arimond M, Wiesmann D, Becquey E et al. (2010) Simple food group diversity indicators predict micronutrient adequacy of women's diets in 5 diverse, resource-poor settings. J Nutr 140, issue 11, 2059S-2069S.

18. Kennedy G, Ballard T \& Dop M (2011) Guidelines for measuring household and individual dietary diversity. http://www.fao.org/fileadmin/user_upload/wa_workshop/ docs/FAOguidelines-dietary-diversity2011.pdf (accessed February 2015).

19. Coates J, Swindale A \& Bilinsky P (2007) Household Food Insecurity Access Scale (HFIAS) for Measurement of Household Food Access: Indicator Guide (v. 3). Washington, DC: Food and Nutrition Technical Assistance Project, Academy for Educational Development.

20. Arimond M, Wiesmann D, Becquey E et al. (2011) Dietary Diversity as a Measure of the Micronutrient Adequacy of Women's Diets in Resource-Poor Areas: Summary of Results from Five Sites. Washingon, DC: FANTA-2 Bridge, FHI 360.

21. Stevens B, Watt K, Clough A et al. (2015) An exploration of maternal dietary diversity and household food security in undernourished pregnant women living in Northern Bangladesh. Int J Food Nutr Public Health 7, 61-69.

22. World Health Organization (1995) Physical Status: The Use and Interpretation of Anthropometry. Report of a WHO Expert Committee. WHO Technical Report Series no. 854. Geneva: WHO.

23. Ververs MT, Antierens A, Sackl A et al. (2013) Which anthropometric indicators identify a pregnant woman as acutely malnourished and predict adverse birth outcomes in the humanitarian context? PLOS Curr 5, ecurrents. dis.54a8b618c1bc031ea140e3f2934599c8.

24. World Health Organization (1995) Maternal anthropometry and pregnancy outcomes. A WHO Collaborative Study. Bull World Health Organ 73, Suppl., 1-98.

25. Kennedy G, Fanou-Fogny N, Seghieri C et al. (2010) Food groups associated with a composite measure of probability of adequate intake of 11 micronutrients in the diets of women in urban Mali. J Nutr 140, issue 11, 2070S-2078S.

26. Huybregts L, Roberfroid D, Lanou H et al. (2009) Prenatal food supplementation fortified with multiple micronutrients increases birth length: a randomized controlled trial in rural Burkina Faso. Am J Clin Nutr 90, 1593-1600. 